\title{
Producing Satisfactory Outcomes in the Implementation Phase of PPP Infrastructure Projects: A Fuzzy Set Qualitative Comparative Analysis of 27 Road Constructions in the Netherlands
}

\author{
Stefan Verweij
}

This is the version of the article that was accepted for publication by the journal. The final, definitive article has been published in International J ournal of Project

Management by Elsevier, all rights reserved.

Verweij, S. (2015). Producing Satisfactory Outcomes in the Implementation Phase of PPP Infrastructure Projects: A Fuzzy Set Qualitative Comparative Analysis of 27 Road Constructions in the Netherlands. International J ournal of Project Management, 33 (8), 1877-1887.

\begin{abstract}
An understudied aspect for the successful completion of PPP infrastructure projects is the extent to which they are satisfactorily implemented. Studying PPP implementation is important though, because well-planned projects can fail if project implementation is inadequately managed. This article aims to find out which management and public-private cooperation approaches produce satisfaction for public procurers in the implementation phase of different kinds of infrastructure projects. To this purpose, twenty-seven Dutch road construction projects are systematically analyzed with fuzzy set qualitative comparative analysis (fsQCA). The results show four configurations that produce satisfaction. It is concluded that externally-oriented management, which is characterized by a stakeholder-oriented project implementation approach, and close public-private cooperation, where public and private partners work together closely and interactively, are important for achieving satisfaction. In less complex projects with narrower scopes, however, the partners may rely on less interactive forms of cooperation, more characterized by monitoring contract compliance.
\end{abstract}

\section{Keywords}

Fuzzy Set Qualitative Comparative Analysis (fsQCA), Management, Public-Private Cooperation, Public-Private Partnership (PPP), Satisfaction, Transportation Infrastructure Project 


\section{Producing Satisfactory Outcomes in the Implementation Phase of PPP Infrastructure Projects: A Fuzzy Set Qualitative Comparative Analysis of 27 Road Constructions in the Netherlands}

\section{Introduction}

Current government policies require that projects are implemented in Public-Private Partnerships (PPPs), using innovative contract types such as Design, Build, Finance, and Maintain (DBFM), with minimal impact on the environment (in terms of, e.g., noise nuisance and road availability) and maximum quality, and for as low as possible budgets. Rijkswaterstaat, the major public procurer of transportation infrastructure in the Netherlands, is a case in point (Rijkswaterstaat, 2014). It has a "the market unless" policy, wants to double its number of DBFM projects by 2020, aspires being a "public-oriented network manager" (Metze, 2010), and it wants to attain the same or higher levels of production (road construction and maintenance) with smaller budgets (Rijkswaterstaat, 2011). Such demands require careful project planning. Many studies have hence been conducted into PPP project planning, focusing especially on issues of procurement, tendering, risk allocation, and PPP finance (see Ke, Wang, Chan, \& Cheung, 2009; Kwak, Chih, \& Ibbs, 2009; Tang, Shen, \& Cheng, 2010).

However, the implementation (i.e., construction and delivery) of PPP projects is complex (cf. Baccarini, 1996; Bertelsen, 2003), involving many stakeholders with different and sometimes unforeseen changing interests, a multitude of regulatory frameworks and restrictions, and complex and sometimes unplanned physical and technical situations (De Bruijn \& Leijten, 2008; Hertogh \& Westerveld, 2010; Teisman, Westerveld, \& Hertogh, 2009; Verweij \& Gerrits, 2015). It means that projects can be well-planned and prepared, but that sound plans and good intensions in planning can nevertheless fail in implementation (e.g., Pressman \& Wildavsky, [1973]1984). A striking example concerns a $€ 2.2$ billion Dutch PPP project for the reconstruction of a $37 \mathrm{~km}$ highway corridor, where the obtained gains in the planning, procurement, and contracting of the project are being lost in the current implementation; newspapers reported budget overruns of $€ 250$ million and increasing due to, inter alia, external project stakeholder complexity (see Verweij, 2015b). It is therefore important to study how infrastructure projects can be successfully implemented. PPP implementation, however, is a relatively underresearched topic in the literature. Research on PPPs in construction focusses instead on planning and pre-contract issues (J ones \& Noble, 2008; Weihe, 2008). One reason for this dearth may be that, whereas the planning of projects is increasingly characterized by open and participatory management approaches, in implementation the project organizations are more closed systems focused on getting the project efficiently and effectively implemented (cf. Dimitriou, Ward, \& Wright, 2013). This complicates access to projects. Relatedly, implementation data are often not made 
available as fears exist that analyses will lead to the identification of culprits for poor outcomes (see Verweij, 2015b).

In response to this research gap, recent case study research has been performed (e.g., Verweij, 2015a; Verweij \& Gerrits, 2015), stressing the importance of externallyoriented management approaches and close and informal public-private cooperation for PPP infrastructure project implementation. Such case studies can provide valuable in-depth insights into managing the complexity of project implementation (cf. Blomquist, Hällgren, Nilsson, \& Söderholm, 2010; Cicmil, Williams, Thomas, \& Hodgson, 2006). However, infrastructure projects are no one size fits all; e.g., a DBFM contract may require different cooperation and management orientations than a Design and Construct $(D \& C)$ contract. It means that case study findings are hard to generalize, exactly because they emphasize the complexity of the infrastructure projects (Verweij \& Gerrits, 2013). What is hence needed is comparative research that can strike a balance between highlighting the unique aspects of projects, as well as the commonalities between them. This article investigates whether different kinds of infrastructure projects - in terms of contract type, project scope, and project size may be (or need to be) managed differently to have a satisfactory implementation process. To that purpose, it studies a medium- $\mathrm{n}$ of project implementations applying fuzzy set qualitative comparative analysis or fsQCA (Ragin, 2008), a methodological approach that was recently proposed for infrastructure project research (Verweij \& Gerrits, 2013), that is well-suited for striking a balance between in-depth insights and generalization.

An important issue here is the outcome measure. Infrastructure projects are implemented in complex social environments, which requires a public procurer to take into account more project outcomes than just the iron triangle's measures of cost, time, and quality (Atkinson, 1999; Dimitriou et al., 2013; J effares, Sullivan, \& Bovaird, 2013). Infrastructure projects may be completed within time and budget and according to specifications, but public values such as transparency or accountability (e.g., Reynaers, 2014) may have been impaired, the public-private relationship may be strained, or external project stakeholders' interests (such as those of citizens, municipalities, or businesses) may have been harmed by the project. Such project outcomes relate to the core responsibilities of government served by public procurers. The iron triangle thus does not capture well the complexity of what constitutes a successful project implementation. The concept of 'satisfaction' is better able to capture the variety of outcomes being produced in implementation (cf. Kärnä, J unnonen, Manninen, \& J ulin, 2013; Lehtiranta, Kärnä, J unnonen, \& J ulin, 2012; Verweij, 2015a; Verweij \& Gerrits, 2015). In this article, satisfaction is the aggregate measure of eight different implementation outcomes, as further detailed later. The research question is: which management and public-private cooperation approaches produce satisfactory outcomes in the implementation phase of different kinds of infrastructure projects?

The article is further structured as follows. In Section 2, literature and previous research are discussed, explaining and motivating the main concepts of this research which form the framework for the analysis. To answer the research question, twenty- 
seven Dutch road constructions are analyzed. Section 3 presents and explains the data and the methods used for the analysis. The analysis and results are provided in Section 4. Section 5 comprises the discussion of the results and limitations of research. Conclusions are drawn in Section 6.

\section{Managing infrastructure project implementation}

This section describes the main concepts that formed the framework of the research. This study focusses on the question which management and public-private cooperation approaches produce satisfactory outcomes in different kinds of projects. Section 2.1 discusses literature to explain the different management and publicprivate cooperation approaches, and the satisfaction outcome measure. Section 2.2 focusses on the characteristics by which projects of different kinds can be distinguished: contract type, project scope, and project size. Table 1 provides a brief overview of the elements in the framework, as further detailed below.

Table 1: Summary of the framework for the analysis

\begin{tabular}{|l|l|l|}
\hline \multicolumn{2}{|l|}{} & Abbreviation \\
\hline Approaches & & \\
\hline Management & $\begin{array}{l}\text { Externally-oriented management } \\
\text { Internally-oriented management }\end{array}$ & $\begin{array}{l}\text { MAN } \\
\text { man }\end{array}$ \\
\hline Public-private cooperation & $\begin{array}{l}\text { Cooperative } \\
\text { Contractual }\end{array}$ & $\begin{array}{l}\text { COOP } \\
\text { coop }\end{array}$ \\
\hline Project characteristics & & \\
\hline Contract type & $\begin{array}{l}\text { Design and Construct } \\
\text { DBFM }\end{array}$ & $\begin{array}{l}\text { CON } \\
\text { con }\end{array}$ \\
\hline Project scope & $\begin{array}{l}\text { Wide scope: integral projects } \\
\text { Narrow scope: single function }\end{array}$ & $\begin{array}{l}\text { SCOPE } \\
\text { scope }\end{array}$ \\
\hline Project size & $\begin{array}{l}\text { Large budget } \\
\text { Small budget }\end{array}$ & $\begin{array}{l}\text { SIZE } \\
\text { size }\end{array}$ \\
\hline
\end{tabular}

\subsection{Management, public-private cooperation, and satisfaction}

In their research on the management of large infrastructure projects, Edelenbos and Klijn (2009) distinguished between project management and process management (see also De Bruijn, Ten Heuvelhof, \& In't Veld, 2010; Edelenbos \& Teisman, 2008). Project management is characterized by a closed, internal project orientation. Indicators are: minimal information is provided to the stakeholder environment about the project's progress, the emphasis is on making progress by speeding up processes, solutions for problems are sought in the project organization so as to promote the project interest, management persists on achieving pre-determined goals regardless of changing circumstances, and communication to the stakeholder environment takes a DAD-strategy (decide, announce, and defend) (Edelenbos \& Klijn, 2009). This internally-oriented approach is often associated with traditional 
modes of management that emphasize the iron triangle measures of success (Edelenbos \& Teisman, 2008). The contrasting process management approach embodies the idea that stakeholder interests in project implementation should be prominently addressed (De Bruijn et al., 2010; Edelenbos \& Klijn, 2009). It is characterized by an open, external project orientation. Indicators are: the project is accessible to interested parties, the emphasis is on creating or maintaining support for the project, solutions are sought together with external stakeholders, management is receptive and flexible to changing circumstances, and communication takes a DDD-strategy (dialogue, decide, and deliver) (see Edelenbos \& Klijn, 2009).

In studying the two management approaches, scholars found that the externally-oriented process management approach is associated with better outcomes (Edelenbos \& Klijn, 2009; Verweij, 2015a; Verweij \& Gerrits, 2015; cf. De Bruijn et al., 2010) since implementing infrastructure projects does not happen in isolation; they are implemented in a social context of external project stakeholders. Because these stakeholders, such as municipalities or interest groups, can hamper or advance project implementation (Olander \& Landin, 2005), for example by granting or not granting permits, this creates interdependencies between the internal and external project stakeholders. This idea is well-documented in network management theory (e.g., Koppenjan \& Klijn, 2004) and stakeholder (management) theories (see Atkin \& Skitmore, 2008). The interdependencies require that addressing stakeholders is crucial so as to achieve satisfactory outcomes (cf. El-Gohary, Osman, \& El-Diraby, 2006).

In carrying out either the project or process management approach, the public principal and private contractor may operate in a less or more cooperative fashion. A distinction can be made between a more cooperative and a more contractual approach (see Edelenbos \& Klijn, 2009; Edelenbos \& Teisman, 2008). The contractual approach is characterized by a strong emphasis on the contract, limited interaction between the public and private partners, and on monitoring compliance with the contract. By contrast, indicators for the more cooperative orientation are: less emphasis on the contract, 'working together' does not stop once the contract is signed but continues in the implementation of the project, and it is characterized by more public-private interaction and mutual trust.

Recent research shows that the cooperative orientation is associated with better outcomes in project implementation (cf. Verweij, 2015a; Verweij \& Gerrits, 2015). Often, when contracts have been signed, the public-private relationship changes from one of collaborative plan development to one in which the contractor alone manages implementation. This, however, may leave potential resources untapped: public principals often have longer-standing relationships with local external project stakeholders than private contractors, and they may use these relationships to manage external stakeholder issues more effectively (Verweij, 2015a; cf. De Schepper, Dooms, \& Haezendonck, 2014). Other studies also indicate the positive relationship between cooperation and outcomes in infrastructure projects (e.g., Chan, Chan, \& Ho, 2003; Larson, 1997). 
In this article, it is understood that a project is successfully being implemented when satisfactory outcomes are produced. Satisfaction entails different things, depending on the goals of the project procurer. The standard outcomes of costs, time, and quality matter, but other outcomes often co-determine whether a project implementation is regarded as successful or not (J effares et al., 2013). Amongst other things, a good public-private relationship, safety, risks, political support, and external stakeholder satisfaction are also important criteria to public procurers (see, e.g., Jeffares et al., 2013; Verweij, 2015b). The concept of satisfaction captures this heterogeneous and multi-dimensional nature of implementation outcomes (cf. Lehtiranta et al., 2012). The actual criteria to measure satisfaction depend on the multiple project goals as set by the procurer and thus have to be determined empirically (cf. Verweij \& Gerrits, 2013; see Section 3.3.1). Satisfaction, then, is the aggregate measure of the different outcomes in a project (see further Section 3.3.1). The study of satisfaction in infrastructure projects receives growing attention, as it is increasingly recognized that satisfaction is able to complement the traditional performance measures of time, cost, and quality (cf. Atkinson, 1999; Kärnä et al., 2013; Lehtiranta et al., 2012; Leung, Ng, \& Cheung, 2004).

\subsection{Contract type, project scope, and project size}

As said, previous research found that a more externally-oriented management approach, and a more cooperative management approach, produces satisfactory outcomes in the implementation phase of projects. That research, however, largely relied on case studies (Verweij, 2015a; Verweij \& Gerrits, 2015). Case studies provide in-depth insights into the reasons for the different satisfaction levels but, by implication, the extent to which these explanations apply to a wider range of projects is not well-known. Interestingly though, a comparison of two case studies showed that the studied projects had different levels of satisfaction and were characterized by different management approaches (Verweij, 2015b). It pointed to three possible explanatory project characteristics for the differences: contract type, project scope, and project size.

- The contract type. The satisfactory project implementation concerned a D\&C contract and the other one a DBFM contract. Assuming a broad definition of PPP, a D\&C project is a partnership where, in contrast to typical public procurement, the contractor is also responsible for the design of the project (Yescombe, 2007). In DBFM contracts (see, e.g., Yescombe, 2007), another kind of PPP, the contractor additionally bears responsibility for project financing and maintenance. Especially characteristic for DBFM contracts is that they insert clear contractual divisions into the partnership (cf. Edelenbos \& Teisman, 2008; Klijn \& Teisman, 2005), instigating a contractual approach to cooperation. Indeed, the philosophy of this contract type is that the market's potential is maximally used when the government is minimally involved in project implementation, only in terms of monitoring contract compliance. Project success largely depends on achieving predefined milestones (because these 
milestones are linked to periodic payments by the public principal, and therefore to the financial constructions between the contractor and lenders).

- The project scope. The satisfactory project implementation involved the reconstruction of a highway into a $2.3 \mathrm{~km}$ long tunnel, combined with inner-city urban development. This integrality of the project, combining different spatial functions, means that many different stakeholders are involved with their interests embedded in the project scope. In fact, local and regional governments were co-principals in the project together with Rijkswaterstaat. For these local project stakeholders, communication and stakeholder management were top priorities and principal and contractor cooperated closely herein. In this way, the broad project scope instigated cooperative and externally-oriented management approaches (cf. Nijkamp, Van der Burch, \& Vindigni, 2002). In contrast, the other project implementation involved one spatial function: the reconstruction of a $37 \mathrm{~km}$ long highway corridor. Rijkswaterstaat bore sole responsibility for the corridor and was the principal of the project. External stakeholders were not closely involved, and rather acted to minimize the impact of the project on their interests. This instigated internally-oriented approaches.

- The project size. A third characteristic in which projects differ is project size is. This was not suggested in the individual case studies as a possible explanatory project characteristic (although the second project is over three times larger than the first one), but other studies have suggested it as a possible determinant for satisfaction in Dutch projects. These studies have suggested that infrastructure projects with smaller budgets tend to have larger average percentages of cost overrun (Verweij, Van Meerkerk, \& Korthagen, 2015; Cantarelli, van Wee, Molin, \& Flyvbjerg, 2012), for instance because the larger projects are linked to the most capable managers (Verweij et al., 2015). Conversely, larger projects, as evidenced by the case studies, may attract more socio-political attention, are riskier, and easier criticized. As said, these are also factors that constitute satisfaction.

In summation, previous research has identified that externally-oriented and cooperative approaches produce satisfaction in project implementation, and in the present study it is investigated whether different kinds of infrastructure projects (in terms of the three characteristics) indeed might be (or need to be) managed differently. To this purpose, twenty-seven Dutch road constructions are comparatively analyzed.

\section{Methods and data}

\subsection{Data collection}

The project implementation data were collected from the Rijkswaterstaat project database, which contains both qualitative and quantitative project data (see Section 3.3). Rijkswaterstaat is the major Dutch procurer of public transportation infrastructure with an annual turnover of approximately $€ 5$ billion (Rijkswaterstaat, 
2014). The selection and collection of the relevant data from the database took place between November 2013 and J une 2014 at the Rijkswaterstaat office in Utrecht (the Netherlands). The database contained 134 projects, twenty-seven of which had data about the project implementation phase that was detailed enough for analysis. A few projects had some missing data, which were completed by consulting MIRT Project Books (e.g., Ministry of Infrastructure and the Environment, 2013) and Rijkswaterstaat managers. ${ }^{1}$ Publishing about the data was allowed, provided that the projects were anonymized. The project-identifiers used in the analysis (see the tables) correspond to the identifiers in the Rijkswaterstaat database.

\subsection{Method: fuzzy set qualitative comparative analysis}

The methodological approach applied in this research is fuzzy set qualitative comparative analysis or fsQCA (Ragin, 2008). Five reasons motivate this choice. First, the configurational nature of fsQCA allows studying management and cooperation in different kinds of projects. In fsQCA, cases (here: the twenty-seven project implementations) are understood as combinations of conditions, i.e., configurations (Schneider \& Wagemann, 2012). This means that different kinds are distinguished in terms of the different possible combinations of the characteristics of contract type, project scope, and project size. Second, because it is a set-theoretic method, fsQCA allows studying how different kinds of projects can be, or need to be, managed differently. In fsQCA, each case has membership between 0 and 1 in each condition (i.e., management, cooperation, contract type, project scope, and project size) and the outcome (i.e., satisfaction) (Ragin, 2008). Each condition has cross-over points that separate qualitatively different cases from each other. By systematically comparing configurations that agree on the outcome but differ in one of the conditions, conditions (or configurations) are identified that are necessary ('need to be') or sufficient ('can be') to produce the outcome. Basically, a condition is necessary when it has to be present for the outcome to occur and it is sufficient if it can produce the outcome by itself (Schneider \& Wagemann, 2012). Third, fsQCA strikes a balance between in-depth case knowledge of the case's complexities on the one hand, and identifying commonalities between cases on the other hand (Verweij \& Gerrits, 2013). Fourth and related, it is very suitable for studying a medium- $n$ of cases, such as the twenty-seven in this article (Rihoux \& Lobe, 2009). Fifth and finally, fsQCA was chosen over other QCA variants, such as crisp-set QCA or multi-value QCA, because of the availability of quantitative data in the Rijkswaterstaat database (see Section 3.3).

The comparative fsQCA process entailed a number of steps (see Verweij, 2015a). After the Rijkswaterstaat project data were collected and coded, the first step in the fsQCA was the construction of the data matrix. This involved calibration: the transformation of the raw project data into fuzzy scores between 0 and 1 by clustering similar cases per condition (Schneider \& Wagemann, 2012). The calibration process

${ }^{1}$ The MIRT is the Multi-Year Plan for Infrastructure, Spatial Planning and Transport. 
and data matrix are important parts of fsQCA and they are reported in Section 3.3. Each row in the data matrix represents a project implementation as a configuration.

The second step was grouping project implementation cases together that exhibited the same configuration. This led to the truth table (see Section 4), listing all the logically possible configurations and showing which configurations are covered by which cases (Schneider \& Wagemann, 2012). With five conditions, there are 32 (i.e., 2^5) logically possible configurations. ${ }^{2}$

The third step was the truth table minimization (see Section 4): comparing truth table rows that agree on the outcome and differ in one of the conditions. It often occurs in fsQCA that truth table rows are covered by cases with opposite outcomes. Such logical contradictions are expressed with the consistency value (Schneider \& Wagemann, 2012). A consistency of 1.0 means a configuration has no contradictions; lower values signal imperfect relationships between the configuration and the outcome. When the consistency of a truth table row was high enough, i.e., when it is higher than the consistency cutoff point (see Schneider \& Wagemann, 2012), then it was assigned the outcome (i.e., 1); if not, it was assigned the non-outcome (i.e., 0) (see Section 4).

The final step was the interpretation and discussion of the results - also called 'solutions' in fsQCA - of the truth table minimization (see Section 5.1), in terms of the cases that are covered by the patterns and in terms of theoretical expectations (Verweij, 2015a). Whereas the previous steps in the fsQCA process quantify the data and analysis to aid a transparent comparison of the medium- $n$ of project implementation cases, this final step is a return to the qualitative data. It is needed to interpret and understand the meaning of the results. The process that is briefly summarized here was iterative (see Rihoux, 2013; Rihoux \& Lobe, 2009); inter alia, contradictions signaled the researcher to return to the qualitative case data, which led to recalibration.

\subsection{Data and calibration}

Prior to the calibration, first the level of completeness was calculated for each project to ensure their comparability. The completeness level is defined as the number of days between the start of the implementation phase (i.e., 'project realization') and the date at which the project data were measured, divided by the number of days between the start of the implementation and the (planned) project delivery date. Depending on the completeness level, the project data were measured at January 1st 2012 (i.e., data about 2011), 2013 (i.e., data about 2012), or 2014 (i.e., data about 2013). For instance, the D\&C project mentioned above started construction on 14-2-2011, has a planned delivery date of 16-12-2016, and the data were measured at J anuary $1^{\text {st }} 2014$. This resulted in a level of completeness of $49 \%$. The average completeness level of the

2 Configurations that are empirically absent (i.e., 'empty truth table rows') are called logical remainders (Schneider \& Wagemann, 2012). These are sometimes used later in the comparative process as counterfactuals, so as to generate more parsimonious patterns (Ragin $\&$ Sonnett, 2005). 
projects was $73 \%$, with a median of $74 \%$, and a standard deviation of $17 \%$. The project implementation cases are thus fairly similar with regard to their completeness.

The calibrated data are shown in Table 2. For the conditions project size (SIZE) and contract type (CONT), and for the outcome satisfaction (SATIS), the raw data are also provided. Due to space restrictions, for the conditions project scope (SCOPE), management (MAN), and cooperation (COOP), only the calibrated data are provided. The data and calibration are now explained in detail (Schneider \&Wagemann, 2010). 
Table 2: Data matrix

\begin{tabular}{|c|c|c|c|c|c|c|c|c|c|c|c|}
\hline \multirow[t]{2}{*}{ Project } & \multirow[t]{2}{*}{ Data } & \multicolumn{2}{|c|}{ CONT } & \multirow[t]{2}{*}{ SCOPE } & \multicolumn{2}{|c|}{ SIZE } & \multirow[t]{2}{*}{ MAN } & \multirow[t]{2}{*}{ COOP } & \multicolumn{2}{|c|}{ SATIS } & \multirow[t]{2}{*}{ Completeness } \\
\hline & & Raw & Cal. & & Raw (k€) & Cal. & & & Raw & Cal. & \\
\hline P.0008 & 2013 & $\mathrm{D} \& \mathrm{C}$ & 1 & 0.33 & 278146 & 0.67 & 0.67 & 0.33 & 13.00 & 0.67 & $59 \%$ \\
\hline P.0029 & 2013 & $\mathrm{D} \& \mathrm{C}$ & 1 & 0.00 & 274787 & 0.67 & 0.33 & 0.00 & 16.00 & 1.00 & $102 \%$ \\
\hline P.0034 & 2013 & $\mathrm{D} \& \mathrm{C}$ & 1 & 1.00 & 620693 & 1.00 & 1.00 & 1.00 & 15.00 & 1.00 & $49 \%$ \\
\hline P.0059 & 2011 & $\mathrm{D} \& \mathrm{C}$ & 1 & 0.33 & 114215 & 0.33 & 0.67 & 0.00 & 15.00 & 1.00 & $70 \%$ \\
\hline P.0077 & 2012 & $\mathrm{D} \& \mathrm{C}$ & 1 & 0.67 & 276962 & 0.67 & 0.67 & 0.33 & 14.00 & 1.00 & $76 \%$ \\
\hline P.0094 & 2013 & $\mathrm{D \& C}$ & 1 & 1.00 & 319694 & 0.67 & 1.00 & 0.67 & 11.67 & 0.33 & $83 \%$ \\
\hline P.0095 & 2012 & $\mathrm{D \& C}$ & 1 & 0.00 & 97741 & 0.33 & 0.67 & 0.33 & 14.67 & 1.00 & $69 \%$ \\
\hline P.0096 & 2011 & D\&C & 1 & 0.00 & 103709 & 0.33 & 0.33 & 0.00 & 12.00 & 0.33 & $85 \%$ \\
\hline P.0102 & 2011 & $D \& C$ & 1 & 0.00 & 48783 & 0.00 & 1.00 & 0.00 & 14.00 & 1.00 & $76 \%$ \\
\hline P.0149 & 2013 & D\&C & 1 & 0.67 & 686322 & 1.00 & 1.00 & 0.33 & 11.00 & 0.33 & $41 \%$ \\
\hline P.0165 & 2011 & D\&C & 1 & 0.33 & 211000 & 0.33 & 0.33 & 0.00 & 9.67 & 0.00 & $96 \%$ \\
\hline P.0179 & 2013 & D\&C & 1 & 0.00 & 121555 & 0.33 & 1.00 & 0.33 & 9.67 & 0.00 & $46 \%$ \\
\hline P.0190 & 2013 & DBFM & 0 & 0.67 & 2268904 & 1.00 & 0.00 & 0.00 & 8.67 & 0.00 & $65 \%$ \\
\hline P.0196 & 2012 & D\&C & 1 & 0.67 & 127013 & 0.33 & 1.00 & 1.00 & 15.33 & 1.00 & $77 \%$ \\
\hline P.0200 & 2011 & $\mathrm{D} \& C$ & 1 & 0.00 & 55391 & 0.00 & 1.00 & 0.00 & 15.00 & 1.00 & $90 \%$ \\
\hline P.0218 & 2012 & DBFM & 0 & 0.67 & 2187177 & 1.00 & 0.67 & 0.33 & 10.67 & 0.33 & $67 \%$ \\
\hline P.0227 & 2013 & $D \& C$ & 1 & 0.67 & 300261 & 0.67 & 0.67 & 0.00 & 11.33 & 0.33 & $56 \%$ \\
\hline P.0247 & 2012 & DBFM & 0 & 0.00 & 683008 & 1.00 & 1.00 & 1.00 & 16.00 & 1.00 & $89 \%$ \\
\hline P.0272 & 2013 & $\mathrm{D} \& \mathrm{C}$ & 1 & 0.33 & 547430 & 0.67 & 0.67 & 0.67 & 14.67 & 1.00 & $74 \%$ \\
\hline P.0319 & 2013 & D\&C & 1 & 0.00 & 54750 & 0.00 & 0.33 & 0.00 & 15.00 & 1.00 & $89 \%$ \\
\hline P.0351 & 2013 & DBFM & 0 & 0.00 & 332229 & 0.67 & 1.00 & 0.67 & 14.67 & 1.00 & $45 \%$ \\
\hline P.0631 & 2013 & $\mathrm{D} \& \mathrm{C}$ & 1 & 0.00 & 9488 & 0.00 & 1.00 & 0.33 & 15.33 & 1.00 & $88 \%$ \\
\hline P.0641 & 2012 & $\mathrm{D} \& \mathrm{C}$ & 1 & 0.00 & 163773 & 0.33 & 1.00 & 0.00 & 16.00 & 1.00 & $101 \%$ \\
\hline P.0755 & 2013 & $D \& C$ & 1 & 0.00 & 159293 & 0.33 & 0.33 & 0.00 & 14.67 & 1.00 & $68 \%$ \\
\hline P.1106 & 2013 & $\mathrm{D} \& C$ & 1 & 0.33 & 21473 & 0.00 & 0.00 & 0.00 & 9.00 & 0.00 & $56 \%$ \\
\hline P.2355 & 2012 & D\&C & 1 & 0.00 & 42997 & 0.00 & 0.00 & 0.33 & 10.67 & 0.33 & $85 \%$ \\
\hline P.2365 & 2012 & $D \& C$ & 1 & 0.00 & 320761 & 0.67 & 1.00 & 0.00 & 12.67 & 0.67 & $63 \%$ \\
\hline
\end{tabular}




\subsubsection{Satisfaction}

Three times a year, the Rijkswaterstaat project managers qualitatively assess their project on multiple outcomes: budget of the project, cash prognosis, achievement of milestones, risk management, administrative-political issues, public-orientedness, cooperation with the market, and safety in the project. ${ }^{3}$ Based on their assessments, the managers score their project on each outcome with either code red (low satisfaction, 0 points), code orange (medium satisfaction, 1 point), or code green (satisfaction, 2 points). These assessments are used by the Rijkswaterstaat project managers to report the implementation progress to the Rijkswaterstaat hierarchy, and they are used by the managers themselves to monitor their project's implementation process. Unavoidably, there is some subjectivity in the assessments because they are qualitative, but factual data about the projects are used by the managers to support their assessments, e.g., they provide examples of events that occurred in the implementation, and they use inter alia financial data, risk management data, and safety reports. It is in the interest of the projects and Rijkswaterstaat that the assessments are as accurate as possible about the state of affairs of the projects. Satisfaction in this article is measured by aggregating the scores for the eight outcomes and then averaging the year's three measurements.

Using the QCA Tosmana software (Cronqvist, 2011), a cluster analysis was performed to group similar projects and separate different ones. This is illustrated in Figure 1. The blocks in the figure represent the twenty-seven cases. The cluster analysis led to the identification of three cross-over points: 10.17, 12.34, and 13.50. As shown in the figure, it means that the twenty-seven projects are divided into four groups. This resulted in the following fuzzy four-value calibration (see Ragin, 2008): 4

- Very low satisfaction: 0.00 (8.67-10.17);

- Low satisfaction: 0.33 (10.18-12.34);

- High satisfaction: 0.67 (12.35-13.50);

- Very high satisfaction: 1.00 (13.51-16.00).

\footnotetext{
3 Three outcomes were not used (i.e., signing of scope documents, capacity of the principal's project team, and evaluation of project quality). These could not be related, based on the qualitative empirical data, to management or public-private cooperation in the project. They concerned Rijkswaterstaatinternal issues rather than project-related issues.

${ }^{4} \mathrm{~A}$ finer-grained scale was not used because the manager's qualitative assessments did not allow the interpretation of small differences in project satisfaction scores.
} 
Figure 1: Calibration for SATIS

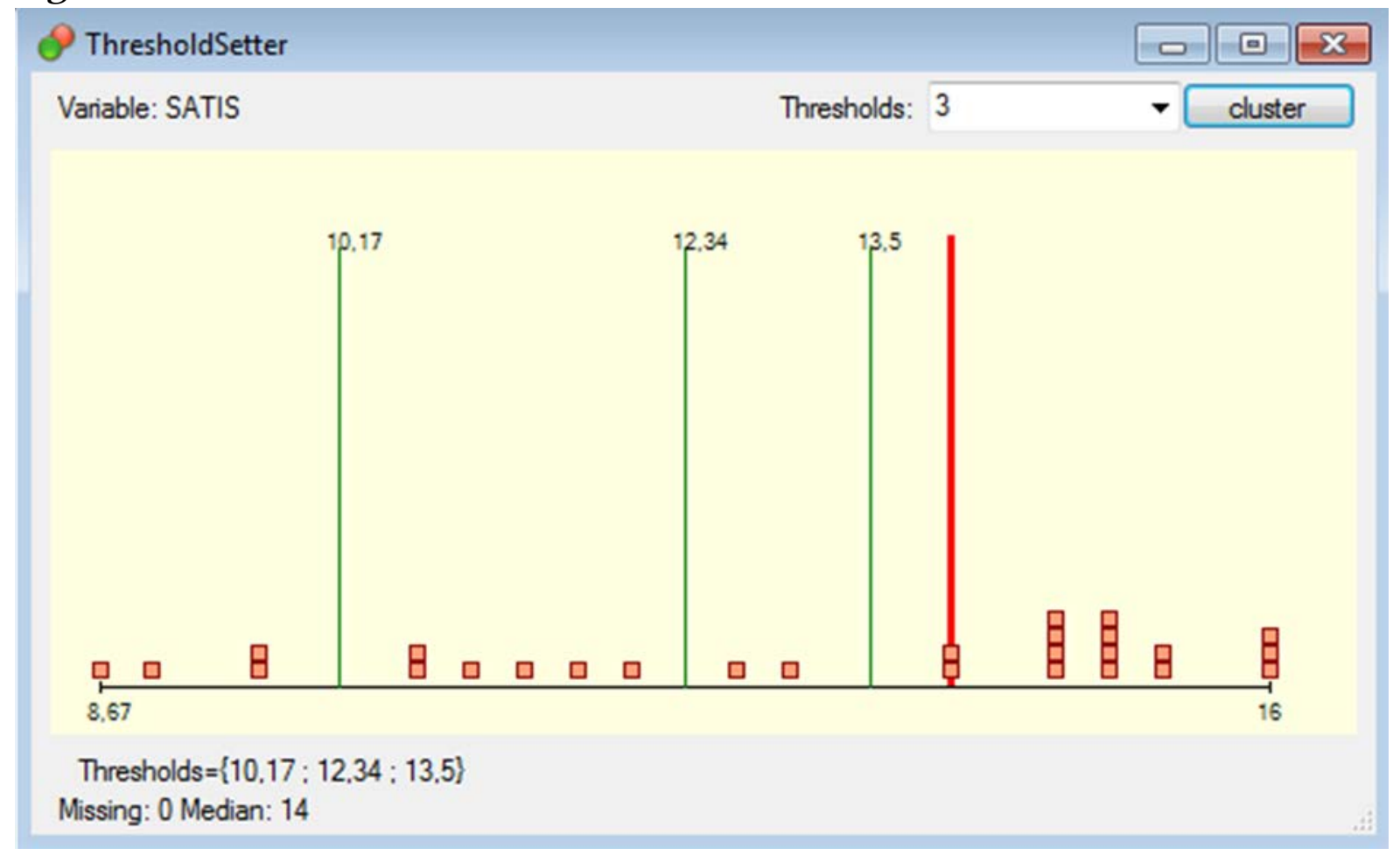

\subsubsection{Management and cooperation}

For the management and cooperation orientations in the projects, only qualitative data were available: general management summaries (one report per year), stakeholder environment reports (three reports per year), and market cooperation reports (three reports per year). The seven reports per project, 202 pages in total, were coded with qualitative data-analysis software (Provalis Research, 2013). E.g., if a text fragment fitted with indicators for externally-oriented management (see Section 2.1) then it was coded as such. Based on the coded data, qualitative project descriptions were constructed and these were cross-compared (cf. Ragin, 1992; e.g., Verweij, 2015a). This process had two iterations - a few small contradictions led to reexamination of some project data, recoding, and a recalibration - as is common in fsQCA (see Section 3.2), and resulted in four clusters of projects, with scores of 0.00, $0.33,0.67$, or 1.00 .

- Low scores (0.00 and 0.33) indicate an (very) internal management orientation and contractual orientation;

- High scores (0.67 and 1.00) indicate an (very) external management orientation and cooperative orientation.

\subsubsection{Contract type, project scope, and project size}

The contract type has two possible values: $\mathrm{D} \& \mathrm{C}$ and $\mathrm{DBFM}$. The $\mathrm{D} \& \mathrm{C}$ projects were assigned a score of 1.00 and the DBFM projects were assigned a score of 0.00 . With regard to the project scope, four project clusters were identified: 
- Standard road construction projects: 0.00;

- Road projects that also included the construction of several new (i.e., not just the renovation of existing ones) tunnels or bridges: 0.33;

- More complex road projects with large new tunnels or bridges: 0.67;

- Integral projects that combine several spatial functions: 1.00 .

The project size was measured by taking the projected final expenditures of the projects. The largest project has a size of $€ 2,269$ million (i.e., over $€ 2.2$ billion). The smallest project is just under $€ 9.5$ million. In the same way as with the outcome measure (cf. Section 3.3.1 and Figure 1), the cluster analysis identified three crossover points: $€ 76.566$ million, $€ 242.894$ million, and $€ 584.061$ million. This resulted in the following calibration (cf. Cantarelli et al., 2012):

- Small projects: 0.00 ( $€ 9.488$ to $€ 76.566$ million);

- Medium projects: 0.33 ( $€ 76.567$ to $€ 242.894$ million);

- Large projects: 0.67 (€ 242.895 to $€ 584.061$ million);

- Very large projects: 1.00 (€ 584.062 to $€ 2.268 .904$ million).

\section{Analysis and results 5}

This section explains the analysis, which was performed with the QCA package in R (Duşa \& Thiem, 2014; Thiem \& Duşa, 2013). The analysis comprises the third and fourth steps in the fsQCA process: the truth table construction, and then the truth table minimization which produces the results (see Section 3.2).

The truth table construction resulted in Table 3 . The consistency cutoff point is 0.875 (see the "incl." column), i.e.: configurations with values of 0.875 or higher are assigned the outcome. Four arguments substantiate this cutoff (see Ragin, 2009; Schneider \& Wagemann, 2012). First, it is well above the lowest 'permitted' value of 0.75 . Second, a clear gap in consistency values can be recognized at 0.875 . Third, the high PRI (i.e., Proportional Reduction in Inconsistency) scores (see Schneider \& Wagemann, 2012) indicate a big difference between the configurations' consistency scores for high satisfaction and low satisfaction. Fourth and most importantly, the cutoff point is substantiated by the examination of the cases covered by the configurations.

\footnotetext{
5 This section focusses on the truth table analysis, which is the analysis of sufficiency. The necessity analysis revealed that there are no conditions or configurations that can be considered necessary according to the commonly accepted consistency threshold of 0.9 (Ragin, 2009). Only three conditions had consistency values above a 0.8 threshold: scope (con. 0.818, cov. 0.775), CONT (con. 0.873, cov. 0.695), and SIZE+coop (con. 0.873, cov. 0.685).
} 
Table 3: Truth table

\begin{tabular}{|l|lllll|l|llll|}
\hline No. & CONT & SCOPE & SIZE & MAN & COOP & SATIS & n & incl. & PRI & Cases \\
\hline 8 & 0 & 0 & 1 & 1 & 1 & 1 & 2 & 1.000 & 1.000 & P.0247, P.0351 \\
28 & 1 & 1 & 0 & 1 & 1 & 1 & 1 & 1.000 & 1.000 & P.0196 \\
21 & 1 & 0 & 1 & 0 & 0 & 1 & 1 & 0.909 & 0.875 & P.0029 \\
32 & 1 & 1 & 1 & 1 & 1 & 1 & 2 & 0.898 & 0.854 & P.0034, P.0094 \\
19 & 1 & 0 & 0 & 1 & 0 & 1 & 7 & 0.884 & 0.864 & P.0059, P.0095, P.0102, P.0179, P.0200, P.0631, \\
& & & & & & & & & & P.0641 \\
23 & 1 & 0 & 1 & 1 & 0 & 1 & 2 & 0.875 & 0.819 & P.0008, P.2365 \\
24 & 1 & 0 & 1 & 1 & 1 & 1 & 1 & 0.875 & 0.834 & P.0272 \\
31 & 1 & 1 & 1 & 1 & 0 & 0 & 3 & 0.724 & 0.568 & P.0077, P.0149, P.0227 \\
17 & 1 & 0 & 0 & 0 & 0 & 0 & 6 & 0.681 & 0.597 & P.0096, P.0165, P.0319, P.0755, P.1106, P.2355 \\
15 & 0 & 1 & 1 & 1 & 0 & 0 & 1 & 0.493 & 0.000 & P.0218 \\
13 & 0 & 1 & 1 & 0 & 0 & 0 & 1 & 0.330 & 0.000 & P.0190 \\
\hline
\end{tabular}


This examination revealed that configurations 8, 21, 23, 24, and 28 are covered by project implementation cases that all have (very) high satisfaction. The configurations with consistency scores below the 0.875 cutoff point are all covered by (a clear majority of) cases with (very) low satisfaction. Two of the configurations above the cutoff point, however, can be considered contradictions but where nevertheless coded as producing satisfactory outcomes. The reasons are as follows.

Configuration 32, covered by cases P.0034 and P.0094, is a contradiction because P.0094 has a satisfaction score of 0.33 (see Table 2). However, the raw satisfaction score for P.0094 is closer to a fuzzy value of 0.67 (i.e., 12.34-11.67=0.67) than to a value of 0.00 (i.e., 11.67-10.18=1.49). Moreover, the managers' qualitative assessments revealed that the project implementation had multiple orange codes not so much because managers were dissatisfied with the implementation, but rather to signal to the Rijkswaterstaat hierarchy that the project had a "high risk profile" and thus required unabated management attention. Given these considerations, the truth table row was still assigned the outcome (i.e., 1).

The second contradiction concerns case P.0179 in configuration 19. The managers' assessments showed that this case is a clear low-performer. Managers identified that the contractor's "knowledge and information systems" were not trustworthy, which also negatively influenced, inter alia, the public-private relationship, the project risks, and the achievement of implementation milestones. Despite this case, the configuration was still assigned the outcome, because the other six cases all have a satisfaction score of 1.00. The contradiction is reflected in the lessthan-perfect consistency score and is discussed in the next section.

The next step is the truth table minimization. The results of the minimization are presented in Table $4 .{ }^{6}$ It shows which management and public-private cooperation approaches produce satisfactory outcomes in different kinds of projects. Uppercase letters in the table indicate a 0.67-1.00 condition score (e.g., SCOPE means a wide scope), and lowercase letters indicate a 0.00-0.33 condition score (e.g., scope means a narrow scope).

\footnotetext{
${ }^{6}$ The table gives the conservative solution. The intermediate solution (see Schneider \& Wagemann, 2012) was also produced by including logical remainders based on two directional expectations: COOP and MAN contribute to producing satisfaction. Comparing the intermediate solution with the conservative solution, it was found that in effect case P.0272 now covered all minimized configurations, resulting is more parsimonious patterns: CONT*MAN*COOP (incl. 0.874, cov.r 0.254), CONT*scope*MAN (incl. 0.858, cov.r 0.545), CONT*scope*SIZE (incl. 0.895, cov.r 0.308), and scope*SIZE*MAN*COOP (incl. 0.929, cov.r 0.236). Because the substantial simplification that was accomplished in the intermediate solution was caused only by P.0272, this was considered a too meager basis for drawing much more parsimonious conclusions. Therefore, this article focusses on the conservative solution. Finally, it must be mentioned (Schneider \& Wagemann, 2010) that the parsimonious solution was: COOP + (scope*SIZE + scope*MAN) (incl. 0.865, cov.r 0.818).
} 
Table 4: Results

\begin{tabular}{|c|c|c|c|c|c|}
\hline & $\begin{array}{l}\text { Minimized } \\
\text { configuration }\end{array}$ & incl. & COV.r & cov.u & Cases \\
\hline 1 & CONT*SCOPE*MAN*COOP & 0.907 & 0.181 & 0.091 & P.0196; P.0034, P.0094 \\
\hline 2 & CONT*scope*MAN*coop & 0.871 & 0.491 & 0.237 & $\begin{array}{l}\text { P.0059, Р.0095, P.0102, } \\
\text { P.0179, P.0200, P.0631, } \\
\text { P.0641; P.0008, P.2365 }\end{array}$ \\
\hline 3 & CONT*scope*SIZE*coop & 0.883 & 0.272 & 0.019 & P.0029; P.0008, P.2365 \\
\hline \multirow[t]{2}{*}{4} & scope*SIZE*MAN*COOP & 0.929 & 0.236 & 0.128 & P.0247, P.0351; P.0272 \\
\hline & Solution & 0.891 & 0.746 & & \\
\hline
\end{tabular}

Notes: uppercase abbreviations indicate a high fuzzy score (0.67-1.00) (i.e., D\&C contracts, wide scope, large project size, externally-oriented management, and a cooperative orientation) and lowercase abbreviations indicate a low fuzzy score $(0.00-0.33)$ (i.e., DBFM contracts, narrow scope, small project size, internally-oriented management, and a contractual orientation).

To complete the fsQCA, an analysis was also performed for low satisfaction, for which a separate truth table was constructed (not reported in the present article). Given the consistency scores in that truth table, only the two configurations covered by cases P.0190 and P.0218 (see Table 3), could be included in the truth table minimization. Both cases have low satisfaction (see Table 2). Combining these two configurations yielded cont*SCOPE*SIZE*Coop as being associated with low satisfaction (with incl. 1.000, cov. 0.154).

\section{Discussion}

\subsection{Interpretation and discussion of the results}

This section concerns the final step in the fsQCA process: the interpretation of the patterns in light of the underlying in-depth case data and theoretical expectations (see Section 3.2).

The first result in Table 4 - CONT*SCOPE*MAN*COOP - states that in projects with a $\mathrm{D} \& \mathrm{C}$ contract and a wide scope, externally-oriented management combined with a cooperative public-private approach produces satisfactory outcomes. This result underscores the importance of externally-oriented management and a cooperative relationship, thus substantiating previous research (see Section 2.1) into the management of PPP projects (Edelenbos \& Klijn, 2009; Verweij \& Gerrits, 2015). The case data showed that in each of the three project implementations covered by the pattern, technically and socio-politically complex and innovative project scopes in two cases inner-city urban development (P.0034 and P.0094) - were implemented in close cooperation with external project stakeholders and between the public and private partners (see also Lenferink, 2014). Stakeholders were co-principals in the project (P.0034), or they were proactively involved in the project implementation (P.0094) to tackle problems upfront. In the projects, there was intensive communication towards citizens via, e.g., Facebook, newsletters, informationmeetings, emails, and construction site visits. The communication monitors deployed 
in the projects found that this was appreciated by the citizens, who showed understanding for the nuisances caused by the projects (cf. Hamersma, Tillema, Sussman, \&Arts, 2014). Of course, the public and private partners in the projects had contracts that clearly defined roles and responsibilities. However, the sharing of knowledge for effective joint communication about the project (P.0034), the joint preparation of contract changes before they are formally submitted (P.0094), or the joint formulation of project goals and "celebration of small successes" (P.0196) proved effective and resulted in satisfaction. All projects had green codes for the outcome 'cooperation with the market', an important aspect of satisfactorily implementing infrastructure projects (cf. Chan et al., 2003; Larson, 1997).

The second result - CONT*scope*MAN*coop - states that in projects with a $D \& C$ contract and a narrower scope, externally-oriented management combined with a contractual public-private approach also produces satisfaction. Compared to the previous pattern, this result shows that externally-oriented management remains important for achieving satisfaction (Edelenbos \& Klijn, 2009; El-Gohary et al., 2006), but that D\&C projects with a narrower scope can also do without intensive public-private cooperation (cf. Verweij \& Gerrits, 2015). The nine cases covered by this pattern were all more or less 'straightforward projects', such as the construction of new roads and additional traffic lanes. The results indicate that, whereas the more multifaceted, socio-politically complex, area-oriented projects involving multiple stakeholders (i.e., the previous pattern) require closer public-private cooperation, the more traditional line-oriented road projects can be implemented with a more contractual approach where the private contractor is more at distance from the public principal (cf. Geraldi, Maylor, \& Williams, 2011; Heeres, Tillema, \& Arts, 2012; Lenferink, 2014). Interestingly, note that the second pattern includes though, as mentioned in Section 4, the contradictory case P.0179. Comparing P.0179 with the other eight cases covered by the pattern, the contractor's "knowledge and information systems" were not functioning well in the project. Because these systems serve to give public contractors the trust that the private partner is in control of the project's quality management - i.e., Rijkswaterstaat monitors contract compliance at distance via system-based contract management - the trust of Rijkswaterstaat in the private partner was low. This made the contractual approach ineffective in this case. This contradictory case thus draws attention to the importance of well-functioning information systems, generating trust between the partners, as a precondition for an effective contractual approach to public-private cooperation.

The result of the analysis for low satisfaction (i.e., cont*SCOPE*SIZE*Coop) further substantiates the above discussed first two results from Table 4. It states that in DBFM projects that are large and multifaceted, a contractually-oriented approach is associated with low satisfaction. Whereas the first two patterns in Table 4 indicated that more complex projects with wide scopes need a cooperative public-private approach and that narrower scopes can do with a contractual approach, the result for the analysis of low satisfaction indicates that when a project with a complex wide scope is not managed with a cooperative approach, low satisfaction is indeed produced as a result. Looking into the case data for of P.0190 which was 
characterized by low satisfaction, it was found that Rijkswaterstaat, driven by the idea that the market was to be left responsible for managing the stakeholder relationships (Rijkswaterstaat's "the market unless" policy), took a background position in the project's implementation phase (i.e., cont instead of CONT). Although it was better connected to the complex institutional landscape of external project stakeholders, Rijkswaterstaat did not make active use of these stakeholder relationships when problems occurred during implementation (cf. Lenferink, 2014; Verweij, 2015a). As a consequence, the problems, most importantly the difficult cooperation between the project and the stakeholder environment, remained unsolved and even deteriorated.

The third result - CONT*scope*SIZE*Coop - offers a nuance to the identified importance of the externally-oriented and cooperative management approaches for producing satisfactory outcomes (cf. Edelenbos \& Klijn, 2009). As can be seen from Table 4 , the pattern is covered by three cases. It states that in D\&C projects with a narrow scope and large size, cooperation can be contractual. Also, it indicates that management does not need to be externally-oriented to achieve satisfaction in implementation: the absence of management in the pattern means that it can be both externally-oriented (i.e., MAN) and internally-oriented (i.e., man). Case P.0029, for instance, was a rather straightforward road construction project that received little media attention, upon which it was decided to only use basic press notifications to inform external stakeholders about road closures for construction. The result suggests that less complex project implementations may need less far-reaching stakeholder management measures, and that more traditional modes of management and project organization can be relied upon (cf. Geraldi et al., 2011; Whitty \& Maylor, 2009).

The fourth and final result from Table 4 - scope*SIZE*MAN*COOP - states that in projects with a narrow scope and a large size, externally-oriented management combined with cooperative public-private cooperation produces satisfactory outcomes in implementation. That is, although the third pattern indicated that it is not necessary in large projects with a narrow scope, externally-oriented management and a cooperative orientation still produce satisfactory outcomes. This further underpins the positive relationship between externally-oriented management and public-private cooperation for achieving satisfaction (Edelenbos \& Klijn, 2009; Verweij \& Gerrits, 2015). Interestingly, two of the projects covered by the pattern have DBFM contracts (i.e., P.0247 and P.0351). Whereas previous PPP studies suggested that DBFM contracts might amplify project-inward and contract-focused orientations (Edelenbos \& Klijn, 2009; Edelenbos \& Teisman, 2008; Verweij, 2015a), the cases P.0247 and P.0351 show that this is not necessarily true.

\subsection{Limitations of the research}

This study has a number of limitations requiring further research. First, although comparatively analyzing twenty-seven projects allowed for generalization, it restricted the extent to which implementation practices can be known in-depth. This is the classical trade-off between in-depth knowledge and the reconstruction of cross- 
case patterns. Future case study research may delve into the implementation processes of the projects to further substantiate the findings of this research. Second, this study focused on how satisfactory outcomes are produced in implementation, but studies into 'project failure', especially when comparing them to 'success cases' can point to valuable additional how not to implement' lessons. The Rijkswaterstaat database, however, contained too few comparable truth table rows (inter alia due to the low consistency scores) to allow an elaborate comparison of cases with low satisfaction. Third, as can be seen from the data matrix (Table 2), there is little variation between the projects regarding contract type. The reason is that few DBFM projects have been or are implemented in the Netherlands. Contract type was still included so as to test the conjecture that the DBFM model might amplify projectinward and contract-focused orientations (Verweij, 2015b). The implication here is that no bold conclusions should be drawn regarding the performance of DBFM in the Netherlands and that more research is needed to generate more conclusive results. Fourth, future research can also include project implementation cases from other countries so as to determine the generalizability of the present research findings beyond the Netherlands. Finally, in this study only project data from the side of the public procurer were collected and analyzed. This means that the private contractors' perspectives on the projects are not included. An interesting avenue for future research is to combine project management data from the public and private partners. This would provide a stronger evidence-base for the research findings.

\section{Conclusions}

This study has multiple implications for PPP practice and research. First, implementers of PPP road infrastructure projects are generally better off when practicing externally-oriented management (cf. Edelenbos \& Klijn, 2009; Verweij 2015b). It is important to stress this (see Verweij, 2015b): in project planning, participatory approaches are often applied which closely involve external stakeholders such as citizens and public permitting organizations. However, when projects enter implementation, the focus tends to shift to managing projects by shielding them from the stakeholder environment as much as possible as it is perceived that this limits interruptions in the project's planning (cf. Dimitriou et al., 2013). However, external stakeholders do not 'disappear' after the project planning phase: externally-oriented management is very important to achieve satisfactory outcomes in dealing with stakeholder complexity in implementation. Second, whereas previous studies stressed the importance of close public-private cooperation in implementing projects (e.g., Verweij, 2015a; Verweij \& Gerrits, 2015), the present research adds that this is particularly true for larger, more complex projects with wider scopes. Especially in DBFM contracts, the intensity of cooperation decreases in implementation as responsibilities are shifted to the private contractor (cf. Edelenbos \& Teisman, 2008; Weihe, 2008), but this study concludes that governments better co-participate in implementation and that they use their recourses (most prominently, their relationships with external stakeholders) to aid satisfactory 
implementation. A nuance to this, thirdly, is that smaller and simpler projects may be managed by less cooperation that is thus more contractual (cf. Geraldi et al., 2011). This can increase efficiency for the public procurer (cf. De Schepper et al., 2014), but provided that well-working and trustworthy management information systems are in place that allow the procurer to monitor the project implementation at distance. Fourth and finally, DBFM contracts are often advocated by governments as the way forward in PPP (e.g., Rijkswaterstaat, 2014). However, previous studies suggested that DBFM does not always produce good results (Verweij, 2015a). This study concludes, in contrast, that this is not necessarily true. This contrasting finding implies that more research into DBFM is needed, to better understand the conditions under which this popular contract type can result in successful projects.

\section{Acknowledgements}

This work was supported by Next Generation Infrastructures [grant 03.24EUR]. The data for this article were provided by Rijkswaterstaat. In particular, Freek Wermer is thanked for making the access to the data possible. The contents of this article do not necessarily represent the views of Rijkswaterstaat, and are thus the researcher's responsibility.

\section{References}

Atkin, B., \& Skitmore, M., 2008. Editorial: stakeholder management in construction. Construction Management and Economics, 26(6), 549- 552.

Atkinson, R., 1999. Project management: cost, time and quality, two best guesses and a phenomenon, it's time to accept other success criteria. International J ournal of Project Management, 17(6), 337- 342.

Baccarini, D., 1996. The concept of project complexity - A review. International J ournal of Project Management, 14(4), 201-204.

Bertelsen, S., 2003. Construction as a complex system. Proceedings of the International Group for Lean Construction, 11.

Blomquist, T., Hällgren, M., Nilsson, A., \& Söderholm, A., 2010. Project-as-practice: In search of project management research that matters. Project Management J ournal, 41(1), 5- 16.

Cantarelli, C. C., van Wee, B., Molin, E. J. E., \& Flyvbjerg, B., 2012. Different cost performance: different determinants? The case of cost overruns in Dutch transport infrastructure projects. Transport Policy, 22, 88-95.

Chan, A. P. C., Chan, D. W. M., \& Ho, K. S. K., 2003. An empirical study of the benefits of construction partnering in Hong Kong. Construction Management and Economics, 21(5), 523- 533.

Cicmil, S., Williams, T., Thomas, J., \& Hodgson, D., 2006. Rethinking project management: Researching the actuality of projects. International J ournal of Project Management, 24(8), 675- 686. 
Cronqvist, L., 2011. Tosmana: Tool for small-n analysis (Version 1.3.2.0). Trier: University of Trier.

De Bruijn, H., \& Leijten, M., 2008. Management characteristics of mega-projects. In H. Priemus, B. Flyvbjerg, \& B. Van Wee (Eds.), Decision making on megaprojects: Cost-benefit analysis, planning and innovation (pp. 23-39). Cheltenham: Edward Elgar.

De Bruijn, H., ten Heuvelhof, E., \& In't Veld, R., 2010. Process management: Why project management fails in complex decision making processes. Berlin: Springer.

De Schepper, S., Dooms, M., \& Haezendonck, E., 2014. Stakeholder dynamics and responsibilities in public-private partnerships: A mixed experience. International J ournal of Project Management, 32(7), 1210- 1222.

Dimitriou, H. T., Ward, E. J ., \&Wright, P. G., 2013. Mega transport projects - Beyond the "iron triangle": Findings from the OMEGA research programme. Progress in Planning, 86, 1- 43.

Duşa, A., \& Thiem, A., 2014. QCA: A package for qualitative comparative analysis (Version 1.1-4).

Edelenbos, J., \& Klijn, E. H., 2009. Project versus process management in publicprivate partnership: Relation between management style and outcomes. International Public Management J ournal, 12(3), 310- 331.

Edelenbos, J., \& Teisman, G. R., 2008. Public-private partnership on the edge of project and process management: Insights from Dutch practice: The Sijtwende spatial development project. Environment and Planning C: Government and Policy, 26(3), 614 - 626.

El-Gohary, N. M., Osman, H., \& El-Diraby, T. E., 2006. Stakeholder management for public private partnerships. International Journal of Project Management, 24(7), 595- 604.

Geraldi, J., Maylor, H., \& Williams, T., 2011. Now, let's make it really complex (complicated): A systematic review of the complexities of projects. International J ournal of Operations \& Production Management, 31(9), 966- 990.

Hamersma, M., Tillema, T., Sussman, J., \& Arts, J., 2014. Residential satisfaction close to highways: The impact of accessibility, nuisances and highway adjustment projects. Transportation Research Part A: Policy and Practice, 59, 106- 121.

Heeres, N., Tillema, T., \&Arts, J ., 2012. Integration in Dutch planning of motorways: From "line" towards "area-oriented" approaches. Transport Policy, 24, 148158.

Hertogh, M. J . C. M., \&Westerveld, E., 2010. Playing with complexity: Management and organisation of large infrastructure projects. Rotterdam: Erasmus University Rotterdam.

J effares, S., Sullivan, H., \& Bovaird, T., 2013. Beyond the contract: The challenge of evaluating the performance(s) of public-private partnerships. In C. Greve \& G. Hodge (Eds.), Rethinking public-private partnerships: strategies for turbulent times (pp. 166- 187). New York: Routledge. 
Jones, R., \& Noble, G., 2008. Managing the implementation of public-private partnerships. Public Money \& Management, 28(2), 109- 114.

Kärnä, S., Junnonen, J.-M., Manninen, A.-P., \& J ulin, P., 2013. Exploring project participants' satisfaction in the infrastructure projects. Engineering Project Organization J ournal, 3(4), 186- 197.

Ke, Y., Wang, S., Chan, A. P., \& Cheung, E., 2009. Research trend of public-private partnership in construction journals. J ournal of Construction Engineering and Management, 135(10), 1076- 1086.

Klijn, E. H., \& Teisman, G. R., 2005. Public-private partnerships as the management of co-production: Strategic and institutional obstacles in a difficult marriage. In G. Hodge \& C. Greve (Eds.), The challenge of public-private partnerships: Learning from international experience (pp. 95-116). Cheltenham: Edward Elgar.

Koppenjan, J. F. M., \& Klijn, E. H., 2004. Managing uncertainties in networks: A network approach to problem solving and decision making. London: Routledge.

Kwak, Y. H., Chih, Y. Y., \& Ibbs, C. W., 2009. Towards a comprehensive understanding of public private partnerships for infrastructure development. California Management Review, 51(2), 51- 78.

Larson, E., 1997. Partnering on construction projects: a study of the relationship between partnering activities and project success. IEEE Transactions on Engineering Management, 44(2), 188- 195.

Lehtiranta, L., Kärnä, S., Junnonen, J.-M., \& J ulin, P., 2012. The role of multi-firm satisfaction in construction project success. Construction Management and Economics, 30(6), 463-475.

Lenferink, S., 2014. Marktbetrokkenheid bij infrastructuurontwikkeling: 10 lessen voor het plan- en aanbestedingsproces. Nijmegen: Radboud Universiteit Nijmegen.

Leung, M., Ng, S. T., \& Cheung, S., 2004. Measuring construction project participant satisfaction. Construction Management and Economics, 22(3), 319- 331.

Metze, M., 2010. Veranderend getij. Amsterdam: Uitgeverij Balans.

Ministry of Infrastructure and the Environment., 2013. MIRT projectenboek 2014. Den Haag: Ministerie van Infrastructuur en Milieu.

Nijkamp, P., Van der Burch, M., \& Vindigni, G., 2002. A comparative institutional evaluation of public-private partnerships in Dutch urban land-use and revitalisation projects. Urban Studies, 39(10), 1865- 1880.

Olander, S., \& Landin, A., 2005. Evaluation of stakeholder influence in the implementation of construction projects. International Journal of Project Management, 23(4), 321- 328.

Pressman, J. L., \& Wildavsky, A., [1973]1984. Implementation: How great expectations in Washington are dashed in Oakland; Or, why it's amazing that federal programs work at all, this being a saga of the economic development administration as told by two sympathetic observers who seek to build morals on a foundation of ruined hopes. Berkeley: University of California Press. 
Provalis Research., 2013. QDA miner lite (Version 1.3).

Ragin, C. C., 1992. Casing and the process of social inquiry. In C. C. Ragin \& H. S. Becker (Eds.), What is a case? Exploring the foundations of social inquiry (pp. 217- 226). Cambridge: Cambridge University Press.

Ragin, C. C., 2008. Redesigning social inquiry: Fuzzy sets and beyond. Chicago: The University of Chicago Press.

Ragin, C. C., 2009. Qualitative comparative analysis using fuzzy sets (fsQCA). In C. C. Ragin \& B. Rihoux (Eds.), Configurational comparative methods: Qualitative comparative analysis (QCA) and related techniques (pp. 87- 121). Thousand Oaks: Sage.

Ragin, C. C., \& Sonnett, J., 2005. Between complexity and parsimony: Limited diversity, counterfactual cases, and comparative analysis. In S. Kropp \& M. Minkenberg (Eds.), Vergleichen in der politik-wissenschaft (pp. 180-197). Wiesbaden: VS Verlag für Sozialwissenschaften.

Reynaers, A., 2014. It takes two to tangle: Public-private partnerships and their impact on public values. Amsterdam: VU University Amsterdam.

Rihoux, B., 2013. Qualitative comparative analysis (QCA), anno 2013: Reframing The Comparative Method's seminal statements. Swiss Political Science Review, 19(2), 233- 245.

Rihoux, B., \& Lobe, B., 2009. The case for qualitative comparative analysis (QCA): Adding leverage for thick cross-case comparison. In D. S. Byrne \& C. C. Ragin (Eds.), The Sage handbook of case-based methods (pp. 222-242). London: Sage.

Rijkswaterstaat., 2011. Ondernemingsplan 2015: Eén Rijkswaterstaat, elke dag beter!. Den Haag: Rijkswaterstaat.

Rijkswaterstaat., 2014. Annual report Rijkswaterstaat: 2013. The Hague: Rijkswaterstaat.

Schneider, C. Q., \& Wagemann, C., 2010. Standards of good practice in qualitative comparative analysis (QCA) and fuzzy-sets. Comparative Sociology, 9(3), 397418.

Schneider, C. Q., \& Wagemann, C., 2012. Set-theoretic methods for the social sciences: A guide to qualitative comparative analysis. Cambridge: Cambridge University Press.

Tang, L., Shen, Q., \& Cheng, E. W. L., 2010. A review of studies on public-private partnership projects in the construction industry. International Journal of Project Management, 28(7), 683-694.

Teisman, G. R., Westerveld, E., \& Hertogh, M. J. C. M., 2009. Appearances and sources of process dynamics: The case of infrastructure development in the UK and the Netherlands. In G. R. Teisman, A. Van Buuren, \& L. M. Gerrits (Eds.), Managing complex governance systems: Dynamics, self-organization and coevolution in public investments (pp. 56- 75). New York: Routledge.

Thiem, A., \& Duşa, A., 2013. Qualitative comparative analysis with R: A user's guide. New York: Springer. 
Verweij, S., 2015a. Achieving satisfaction when implementing PPP transportation infrastructure projects: A qualitative comparative analysis of the A15 highway DBFM project. International J ournal of Project Management, 33(1), 189- 200.

Verweij, S., 2015b. Once the shovel hits the ground: Evaluating the management of complex implementation processes of public-private partnership infrastructure projects with qualitative comparative analysis. Rotterdam: Erasmus University Rotterdam.

Verweij, S., \& Gerrits, L. M., 2013. Understanding and researching complexity with qualitative comparative analysis: Evaluating transportation infrastructure projects. Evaluation, 19(1), 40- 55.

Verweij, S., \& Gerrits, L. M., 2015. How satisfaction is achieved in the implementation phase of large transportation infrastructure projects: A qualitative comparative analysis into the A2 tunnel project. Public Works Management \& Policy, 20(1), 5- 28.

Verweij, S., Van Meerkerk, I. F., \& Korthagen, I. A., 2015. Reasons for contract changes in implementing Dutch transportation infrastructure projects: An empirical exploration. Transport Policy, 37(1), 195- 202.

Weihe, G., 2008. Public-private partnerships and public-private value trade-offs. Public Money \& Management, 28(3), 153- 158.

Whitty, S. J., \& Maylor, H., 2009. And then came complex project management (revised). International J ournal of Project Management, 27(3), 304- 310.

Yescombe, E. R., 2007. Public-private partnerships: Principles for policy and finance. Burlington: Butterworth-Heinemann. 